\title{
Genome sequence analysis of the beneficial Bacillus subtilis PTA-271 isolated from a Vitis vinifera (cv. Chardonnay) rhizospheric soil: assets for sustainable biocontrol
}

Catarina Leal ${ }^{1}$, Florence Fontaine ${ }^{1}$, Aziz Aziz ${ }^{1}$, Conceiçao Egas², Christophe Clément ${ }^{1}$ and Patricia Trotel-Aziz ${ }^{1 *}$ (D)

\begin{abstract}
Background: Bacillus subtilis strains have been widely studied for their numerous benefits in agriculture, including viticulture. Providing several assets, $B$. subtilis spp. are described as promising plant-protectors against many pathogens and as influencers to adaptations in a changing environment. This study reports the draft genome sequence of the beneficial Bacillus subtilis PTA-271, isolated from the rhizospheric soil of healthy Vitis vinifera cV. Chardonnay at Champagne Region in France, attempting to draw outlines of its full biocontrol capacity.

Results: The PTA-271 genome has a size of 4,001,755 bp, with $43.78 \%$ of $G+C$ content and 3945 protein coding genes. The draft genome of PTA-271 putatively highlights a functional swarming motility system hypothesizing a colonizing capacity and a strong interacting capacity, strong survival capacities and a set of genes encoding for bioactive substances. Predicted bioactive compounds are known to: stimulate plant growth or defenses such as hormones and elicitors, influence beneficial microbiota, and counteract pathogen aggressiveness such as effectors and many kinds of detoxifying enzymes.
\end{abstract}

Conclusions: Plurality of the putatively encoded biomolecules by Bacillus subtilis PTA-271 genome suggests environmentally robust biocontrol potential of PTA-271, protecting plants against a broad spectrum of pathogens.

Keywords: Genome draft, Beneficial bacterium, Bacillus subtilis PTA-271, Grapevine trunk diseases, Grey mold, Wide protective spectrum, Sustainable biocontrol

\footnotetext{
*Correspondence: patricia.trotel-aziz@univ-reims.fr

'SFR Condorcet - FR CNRS 3417, University of Reims Champagne-Ardenne, Induced Resistance and Plant Bioprotection (RIBP) - EA 4707, BP1039, Cedex 2, F-51687 Reims, France

Full list of author information is available at the end of the article
}

C C The Author(s). 2021 Open Access This article is licensed under a Creative Commons Attribution 4.0 International License, which permits use, sharing, adaptation, distribution and reproduction in any medium or format, as long as you give appropriate credit to the original author(s) and the source, provide a link to the Creative Commons licence, and indicate if changes were made. The images or other third party material in this article are included in the article's Creative Commons licence, unless indicated otherwise in a credit line to the material. If material is not included in the article's Creative Commons licence and your intended use is not permitted by statutory regulation or exceeds the permitted use, you will need to obtain permission directly from the copyright holder. To view a copy of this licence, visit http://creativecommons.org/licenses/by/4.0/ The Creative Commons Public Domain Dedication waiver (http://creativecommons.org/publicdomain/zero/1.0/) applies to the data made available in this article, unless otherwise stated in a credit line to the data. 


\section{Background}

Bacillus subtilis is a Gram-positive endospore-forming bacterium from Bacillus genera considered as a promising plant beneficial organism that can survive in the soil for extended time periods under harsh environmental conditions [1]. Benefits of species from the Bacillus group are well described in many sectors of industry, agriculture and viticulture [2]. Focusing on the B. subtilis species, it has been described to provide plants with a broad range of benefits that include induced systemic resistance (ISR) upon pathogen attacks, growth promotion, or the direct control of plant pathogens [3-6].

Primed defenses during ISR are regulated either by jasmonic acid (JA) and ethylene (ET) signaling or by salicylic acid (SA) signaling [7-10]. Beneficial microorganisms may modulate the plant hormonal balance by either altering hormone synthesis or by producing similar hormones or their precursors (ET, SA, auxins, gibberellins, cytokinins, polyamines...) [8]. Numerous bacterial elicitors of ISR are also reported in several plant species, such as exopolysaccharides (EPS), lipopolysaccharides (LPS), siderophores such as the iron-regulated pyoverdin, iron, flagella, biosurfactants, N-acyl-L-homoserine lactone, $\mathrm{N}$-alkylated benzylamine and volatile compounds $[8,9,11,12]$. Some of these have already been identified in species of $B$. subtilis or Bacillus genera $[8,11,13,14]$. Changes in the phytohormonal-balance also impact plant growth and development, since the reduction of ET may promote plant growth $[8,15,16]$. Microbiota support plant growth and development by modulating nutrient availability through mineralization and chelation, as well as through the production of volatile compounds that support biocontrol [17, 18]. Efficient beneficial effects of Bacillus spp. also assume direct and indirect bacterium and microbiota preservation, upon abiotic and biotic stressful conditions [8, 19]. When biocontrol agents protect themselves through extrusion transporters, detoxifying enzymes, quenching enzymes and pathogen homologous enzymes, they also contribute indirectly to plant protection [8]. Finally, B. subtilis produces an extensive range of antimicrobial molecules, chelators and lytic enzymes that limit pathogen fitness and aggressiveness [20]. According to literature, these beneficial molecules include ribosomally synthesized antimicrobial peptides (RP, including the post-translationally modified peptides RiPP), non-ribosomally synthesized peptides (NRP), polyketides (PK), as well as other uncommon antimicrobial volatile compounds (the inorganic and organic ViCs and VOCs, respectively) and terpenoid secondary metabolites as listed in Table 1. Individual strain specificities may thus impact both biochemical conditions and species ratios, and in turn interactions among complex microbial communities and their hosts.

Focusing on B. subtilis PTA-271, its protective effect has been published in grapevine against Neofusicoccum parvum and Botrytis cinerea [3-5], the causal agents of Botryosphaeria dieback and grey mold respectively. The ability of $B$. subtilis species to sporulate in order to resist climate changes and common disinfectants [1], combined with the fact that B. subtilis PTA-271 is a nonpathogenic species, make this microorganism suitable to control a wide spectrum of pathogens among which the most economically significant grapevine trunk disease (GTD) pathogens currently lack of efficient control strategies [3, 22]. In this study, we report the draft genome sequence of the $B$. subtilis strain PTA-271, analyze and compare with other known Bacillus strains sequences, to expand our knowledge of B. subtilis PTA-271 benefits, as well as design efficient and sustainable biocontrol strategies for viticulture.

\section{Methods}

\section{B. subtilis PTA-271 GENERAL INFORMATION AND FEATURES}

B. subtilis PTA-271 was isolated in 2001 (Table 2) from the rhizospheric soil of healthy Chardonnay grapevines (V. vinifera L., cv Chardonnay) from a vineyard located in Champagne (Marne, France). Rhizospheric samples were directly suspended in a sterile $0.85 \% \mathrm{NaCl}$ solution ( $1 \mathrm{~g}$ of soil: $10 \mathrm{ml}$ of $\mathrm{NaCl}$ ) and bacterial isolates were obtained by serial dilutions of the soil samples $\left(10^{7}, 10^{3}\right.$, $10^{2} \mathrm{cfu} / \mathrm{g}$ soil) in triplicate onto LB-agar (Luria-Bertaniagar), King's B-agar and glycerol-arginine-agar plates by incubating at $30^{\circ} \mathrm{C}$ for $24-72 \mathrm{~h}$. All different colonies were then re-isolated on LB-agar, cultured in $\mathrm{LB}$ at $30^{\circ} \mathrm{C}$ for $24 \mathrm{~h}$ and screened for their protective role against Botrytis cinerea by using grapevine plantlet leaf assays pretreated with bacterium [4]. Selected biocontrol microorganisms were then identified, calculated to establish the density formula and stored in a sterile $25 \%$ glycerol solution at $-80{ }^{\circ} \mathrm{C}$ for complementary purposes. The classification and general features of $B$. subtilis PTA-271 are in Table 2. The taxonomic information for this strain was already described by Trotel-Aziz et al. (2008) [4] and remains unaltered to this date.

\section{B. subtilis PTA-271 GENOMIC SEQUENCING INFORMATION Genome project history}

B. subtilis PTA-271 was selected for sequencing due to its efficient capacity to protect grapevine against several pathogens with distinct lifestyles such as Botrytis cinerea and Neofusicoccum parvum [3-5]. This beneficial microorganism can not only modulate grapevine defenses, but also antagonize the growth of pathogens and detoxify aggressive molecules. These beneficial bacteria provide protection against a broad spectrum of pathogens, due to its genetic traits of physical and chemical tolerance (endospore forming, withstand large $\mathrm{pH}$ and salinity range, Table 2). Altogether, there are advantages to sequence 
Table 1 Bacillus subtilis known antimicrobial molecules, chelators and lytic enzymes [6, 20, 21]

\begin{tabular}{|c|c|c|}
\hline \multirow{4}{*}{$\mathbf{R P}$} & Bacteriocins & $\begin{array}{l}\text { such as the lantibiotics: lanthionine, nysin and subtilin, the } \\
\text { pediocin-like peptides, the thuricin-like peptides and other linear } \\
\text { peptides }\end{array}$ \\
\hline & $\begin{array}{l}\text { Quorum quenching } \\
\text { enzymes }\end{array}$ & such as lactonase, decarboxylase, acylase and deaminase), \\
\hline & $\begin{array}{l}\text { Cell wall degrading } \\
\text { enzymes (CWDE) }\end{array}$ & such as cellulases, proteases, chitinases, glucanases, etc... \\
\hline & Detoxifying-enzymes & such as transferases and oxygenases \\
\hline \multirow{3}{*}{ NRP } & $\begin{array}{l}\text { Thiotemplate NRPs- } \\
\text { lipopeptides }\end{array}$ & such as fengycin, surfactin, iturin, bacillomycin \\
\hline & $\begin{array}{l}\text { Thiotemplate NRPS- } \\
\text { siderophores to compete } \\
\text { pathogen nutrition }\end{array}$ & such as the catecholic siderophores: itoic acid and bacillibactin \\
\hline & Non-thiotemplate NRPs & $\begin{array}{l}\text { such as the di- and tri- peptides rhizocticins, bacylisin, } \\
\text { chlorotetain and the cyclic polypeptides bacitracin and } \\
\text { mycobacillin }\end{array}$ \\
\hline PK & \multicolumn{2}{|c|}{$\begin{array}{l}\text { Acetogenins, ansamycins, enedyines, macrolides, polyenes, polyethers and tetracyclines } \\
\text { (such as bacillaene, difficidin and macrolactin that selectively inhibit protein synthesis) }\end{array}$} \\
\hline VICs & \multicolumn{2}{|c|}{$\begin{array}{l}\text { Carbonated, hydrogenated, sulfur or nitrogen-containing compounds (such as } \mathrm{H}_{2}, \mathrm{HCN} \text {, } \\
\mathrm{H}_{2} \mathrm{~S}, \mathrm{NH}_{3} \text { ). }\end{array}$} \\
\hline \multirow{3}{*}{ VOCs } & $\begin{array}{l}\text { Fatty acids derivatives } \\
(70 \% \text { of the VOC })\end{array}$ & such as the benzenoids 1,3-butadiene or 2,3-butanediol \\
\hline & $\begin{array}{l}\text { Sulfur-containing VOCs } \\
\text { (VSCs) }\end{array}$ & $\begin{array}{l}\text { such as dimethyl disulfide DMDS, dimethyl trisulfide DMTS, S- } \\
\text { methyl thioacetate or S-methyl butanethioate }\end{array}$ \\
\hline & $\begin{array}{l}\text { Nitrogen-containing } \\
\text { VOCs }\end{array}$ & $\begin{array}{l}\text { such as azoles, pyrazines, pyridines, pyridazines, and } \\
\text { pyrimidines }\end{array}$ \\
\hline $\begin{array}{l}\text { Other II } \\
\text { metabolites }\end{array}$ & Terpenoids & such as isoprene and monoterpene a-terpineol \\
\hline
\end{tabular}

$R P$ Ribosomally synthesized antimicrobial peptides (including the post-translationally modified peptides RiPP), NRP Non-ribosomally synthesized peptides, PK Polyketides, VIC Inorganic antimicrobials volatile compounds, VOC Organic antimicrobials volatile compounds

the B. subtilis PTA-271 genome to better understand its key beneficial levers and develop better sustainable biocontrol strategies regardless of field conditions or soil parameters ( $\mathrm{pH}$, salinity, etc.).

The whole genome shotgun project has been deposited at DDBJ/ENA/GenBank under the accession JACERQ000000000. The version described in this paper is version JACERQ000000000 and all related information is represented in Table 3.

\section{Genomic DNA preparation}

Genomic DNA of B. subtilis PTA-271 was extracted using the Wizard $^{\oplus}$ Genomic DNA Purification kit (Promega), from the pellet of a $1 \mathrm{~mL}$-overnight culture incubated at $28{ }^{\circ} \mathrm{C}$ in LB medium. DNA integrity was confirmed on a $0.65 \%$ agarose gel electrophoresis in TAE buffer. DNA concentration and quality were read from $1 \mu \mathrm{L}$ of DNA with the NanoDrop-ONE spectrophotometer (Ozyme).

\section{Library preparation and genome sequencing}

DNA library for bacterial genome sequencing was prepared from 0.5 nanograms of high-quality genomic DNA using the Nextera XT DNA Sample Preparation Kit (Illumina, San Diego, USA) and sequenced using pairedend (PE) $2 \times 300 \mathrm{bp}$ on the $\mathrm{MiSeq}^{\circ}$ Illumina $^{\circ}$ platform at Genoinseq (Cantanhede, Portugal). All the procedures were performed according to standard manufacturer protocols.

\section{Genome assembly and annotation}

Sequenced reads were demultiplexed automatically by the Illumina ${ }^{\circledR}$ Miseq $^{\oplus}$ sequencer using the CASAVA package (Illumina, San Diego, USA) and quality-filtered with Trimmomatic version 0.30 [24]. High-quality adapter-free reads were assembled with SPAdes version 3.9.0 [25] and contigs with size $<500$ bp or coverage lower 10x were removed from the assembly. Assembly metrics were calculated with Quast version 4.6.1 [26]. 
Table 2 Classification and features of Bacillus subtilis PTA-271 according to MIGS recommendations [23]

\begin{tabular}{|c|c|c|c|}
\hline MIGS ID & Property & Term & Evidence code \\
\hline & Classification & Domain Bacteria & TAS \\
\hline & & Phylum Firmicutes & TAS \\
\hline & & Class Bacilli & TAS \\
\hline & & Order Bacillate & TAS \\
\hline & & Family Bacilaceae & TAS \\
\hline & & Genus Bacillus & TAS \\
\hline & & Sepecies Bacillus subtilis & TAS \\
\hline & & Strain: PTA-271 & \\
\hline & Gram strain & Gram-positive & IDA \\
\hline & Cell shape & Rod-shaped & IDA \\
\hline & Motility & Motile & NAS \\
\hline & Sporulation & spore-forming & NAS \\
\hline & Temperature range & Unreported & \\
\hline & Optimum temperature & $37^{\circ} \mathrm{C}$ & NAS \\
\hline & $\mathrm{pH}$ range, optimum & $4-9.5,8$ & NAS \\
\hline & Carbon source & Organic carbon compounds & NAS \\
\hline MIGS-6 & Habitat & Soil, grapevine & IDA \\
\hline MIGS-6.3 & Salinity & $0-50 \mathrm{~g} / \mathrm{l}$; salt tolerant & NAS \\
\hline MIGS-22 & Oxygen requirement & Aerobic & NAS \\
\hline MIGS-15 & Biotic relationship & Free-living & IDA \\
\hline MIGS-14 & Pathogenicity & Non-pathogenic & NAS \\
\hline MIGS-4 & Geographic location & Champagne region, Marne, France & IDA \\
\hline MIGS-5 & Sample collection & 2001 & IDA \\
\hline MIGS-4.1 & Latitude & $49^{\circ} 15^{\prime} 15^{\prime}, \mathrm{N}$ & \\
\hline MIGS-4.2 & Longitude & $4^{\circ} 09^{\prime} 28^{\prime \prime} \mathrm{E}$ & \\
\hline MIGS-44 & Altitude & $105-206 \mathrm{~m}$ & \\
\hline
\end{tabular}

${ }^{a}$ Evidence codes (from the Gene ontology project [58] - IDA Inferred from Direct assay, TAS Traceable Author Statement (i.e., a direct report exists in the literature), NAS Non-traceable Author Statement (i.e., not directly observed from the living, isolated sample, but based on a generally accepted property for the species, or anecdotal evidence)

Contigs were checked for contamination and completeness using CheckM 1.0.9 [27]. Coding gene predictions were made with Prodigal version 2.6 [28], rRNA and tRNA genes were detected using Barrnap version 0.8 and CRISPR regions were detected by Minced version 0.2.0. Coding gene annotation was performed with Prokka version 1.12 [29] using the following repositories: SwissProt (The UniProt Consortium, 2017), HAMAP [30], TIGRFAMs [31] and Pfam [32]. Coding genes were also annotated for Pathway using KEGG [33], for peptidases using MEROPS [34] and for carbohydrate-active enzymes with $\mathrm{dbCaN}$ [35].

\section{Results and discussion}

\section{B. subtilis PTA-271 GENOME PROPERTIES AND COMPARISON WITH OTHER BACILLUS STRAINS}

The general features of $B$. subtilis PTA-271 are in Table 4 and Fig. 1, performed using Artemis version 16.0.0. The draft genome sequence of B. subtilis PTA271 presented an estimated genome size of 4,001,755 bp divided in 20 contigs. The $\mathrm{G}+\mathrm{C}$ content of this sequence was $1,751,999 \mathrm{bp}$, representing about $43.78 \%$ of the whole genome. Genome analysis showed that B. subtilis PTA-271 contained 4038 genes, among which 3945 $(97.69 \%)$ were protein coding genes. This genome draft 
Table 3 Bacillus subtilis PTA-271 genomic sequencing information

\begin{tabular}{lll}
\hline MIGS ID & Property & Term \\
\hline MIGS 31 & Finishing quality & High-quality draft \\
MIGS28 & Libraries used & Illumina paired-end library $(2 \times 300$ bp insert size $)$ \\
MIGS29 & Sequencing platforms & Illumina MiSeq \\
MIGS31.2 & Fold coverage & $300 \mathrm{X}$ \\
MIGS30 & Assemblers & SPAdes \\
MIGS32 & Gene calling method & Prodigal v.2.6 \\
& Locus tag prefix & H0Z15 \\
& WGS accession : & \\
& SUBID & SUB7775359 \\
& BioProjet & PRJNA646528 \\
& BioSample & SAMN15546529 \\
& DDBJ/ENA/GenBank accession & JACERQ000000000 \\
& Source Material Identifier & Bacillus subtilis PTA-271 \\
MIGS13 & Project relevance & Biocontrol, Grapevine, GTD \\
&
\end{tabular}

predicts 92 RNA genes among which 11 rRNA genes were identified and no CRISPR repeats. From 4,001,755 bp of the genome size, 3,550,299 bp correspond to coding genes representing $88.73 \%$ of the whole genome. From this, 3440 genes had function prediction, 3183 were assigned to the COG categories described in Table 5, and 3517 genes had Pfam domain descriptions.

\section{B. subtilis PTA-271 ASSETS FOR PLANT SUSTAINABLE BIOCONTROL}

Bacillus species offer a broad range of benefits to plants: (1) plant growth promotion, (2) induced systemic plant defenses and protection against pathogens, and (3) prevention of pathogen fitness or aggressiveness, by producing many compounds able to interact with the host plants, the pathogens or their tripartite intricate communication. Considering this, the genome analysis of B. subtilis PTA-271 tried to highlight some useful characteristics directly or indirectly beneficial for a sustainable plant protection against a broad spectrum of pathogens.

\section{Motility and adhesion: assets for plant root colonization}

Motility of a bacterium is due to the flagellum, enabling it to move towards a vital nutrient source (chemotaxis). In this sense, B. subtilis PTA-271 contains genes (Supplementary Table S1) putatively encoding for flagella maintenance (flh genes) and chemotaxis (che genes). Once reaching a comfortable area, adhesion is due to bacterium pili,

Table 4 Genome statistics

\begin{tabular}{lll}
\hline Attribute & Value & $\%$ of Total \\
\hline Genome size (bp) & $4,001,755$ & 100 \\
DNA coding (bp) & $3,550,899$ & 88.73 \\
DNA G + C (bp) & $1,751,999$ & 43.78 \\
DNA scaffolds & 20 & - \\
Total genes & 4,038 & 100 \\
Protein coding genes & 3,945 & 97.69 \\
RNA genes & 92 & 2.27 \\
Genes with function prediction & 3,440 & 85.19 \\
Genes assigned to COGs & 3,183 & 78.82 \\
Genes with Pfam domains & 3,517 & 87.10 \\
CRISPR repeats & 0 & 0 \\
\hline
\end{tabular}

${ }^{a}$ The total is based on either the size of genome in base pairs or the total number of genes in the predicted genome 


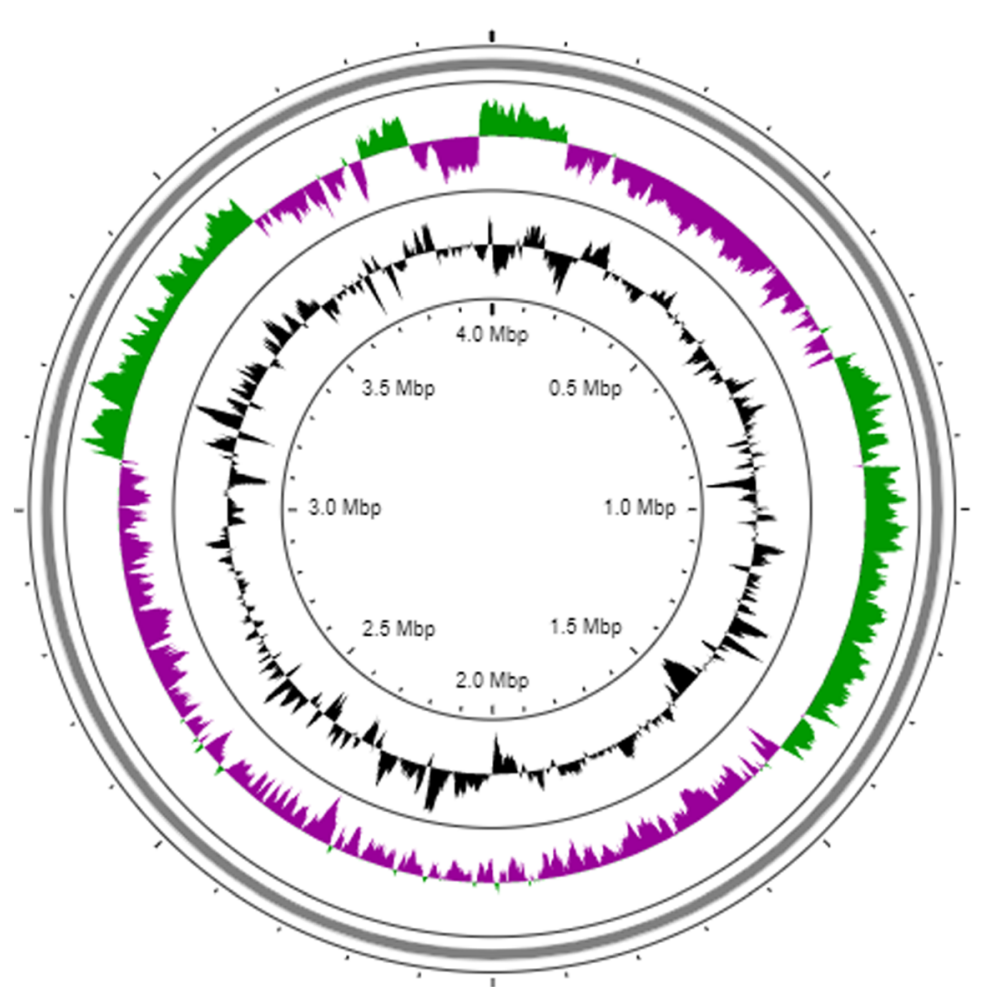

GC Skew+

GC Skew-

GC Content

Fig. 1 Circular map of the Bacillus subtilis PTA-271 genome. Map generated with CGView server [36]

allowing the initiation of biofilm formation where both chemotaxis and gene exchanges among microorganisms of microbiota can be amplified.

B. subtilis spp. are also described for their strong swarming motility [37]. The gene $s w r C$ putatively encoding for swarming motility protein is predicted in the genome of B. subtilis PTA-271 (Supplementary Table S1). Swarming motility requires the production of functional flagella, pili and surfactant to reduce surface tension.

Motilities and adhesion are considered advantageous characters for a successful host colonization and B. subtilis spp. are already described to grow in biofilm mode involved in root colonization [38]. To this end, the transcription factors (TF) Spo0A and AbrB were described as positive and negative regulators of biofilm formation, respectively [39]. Genes putatively encoding for these 2 TFs are also predicted in the genome of $B$. subtilis PTA-271 as SpoOA and $A b r B$ (Supplementary Tables S1 and S2).

Beneficial microorganisms that successfully colonize the plant, particularly by the root system, would be advantageous, both for plant growth promotion and for plant biocontrol [40, 41].

\section{Biofertilizing and morphogenic effects: assets for plant vigor} Plant nutrition depends on soil retention capacity of minerals and nutrient availabilities, thus both on chelating process, mineralization by decomposers and minerals bioavailability towards the plant consumer. Upon nitrogen starvation, some bacteria are described to upregulate the ure gene cluster, since urea is an easy nitrogen source. Such ure genes are predicted in B. subtilis PTA-271 genome (ure $A$, ure $B$, ure $C$ ). This cluster of genes is known to be controlled by the global nitrogen-regulatory protein TnrA, also predicted in B. subtilis PTA-271 genome (Supplementary Table S2). Regarding other nutrient access due to phosphate-solubilizing bacteria (PSB) [6, 42, 43], genes encoding for proteins involved in the production of gluconic acid and precursor of citric acid are also predicted in the genome of B. subtilis PTA-271 (S19-40_03830, S1940_03828). Organic acids may lower the soil $\mathrm{pH}$ to solubilize phosphate and thus increase its availability to the plant [42]. Bacterial secondary metabolites (PyrroloQuinoline Quinone, PQQ) are also known to control gluconic acid production [44], and B. subtilis PTA-271 has 3 genes predicted to be related to PQQ production $p q q L, p q q F$ and pqqC [45]. Additionally, B. subtilis PTA-271 contains the phytase gene phy, described in the other Bacillus spp. to encode for phosphatases able to hydrolyze organic complex in order to liberate phosphate and make it available for plants [46]. Iron is another very important nutrient for plant growth and development. B. subtilis PTA-271 possesses the fur gene (Supplementary Table S2) described in the literature to encode for a regulatory protein coordinating the homeostasis of iron uptake depending on its 
Table 5 Number of genes associated with general COG functional categories

\begin{tabular}{lccl}
\hline Code & Value & \%age $\mathrm{a}^{\mathrm{a}}$ & Description \\
\hline $\mathrm{J}$ & 173 & 4.38 & Translation, ribosomal structure and biogenesis \\
$\mathrm{A}$ & 0 & 0 & RNA processing and modification \\
$\mathrm{K}$ & 313 & 7.93 & Transcription \\
$\mathrm{L}$ & 118 & 2.99 & Replication, recombination and repair \\
$\mathrm{B}$ & 1 & 0.02 & Chromatin structure and dynamics \\
$\mathrm{D}$ & 39 & 0.98 & Cell cycle control, cell division, chromosome partitioning \\
$\mathrm{V}$ & 59 & 1.49 & Defense mechanisms \\
$\mathrm{T}$ & 171 & 4.33 & Signal transduction mechanisms \\
$\mathrm{M}$ & 210 & 5.32 & Cell wall/membrane/envelope biogenesis \\
$\mathrm{N}$ & 62 & 1.57 & Cell motility \\
$\mathrm{U}$ & 49 & 1.24 & Intracellular trafficking, secretion, and vesicular transport \\
$\mathrm{O}$ & 109 & 2.76 & Posttranslational modification, protein turnover, chaperones \\
$\mathrm{C}$ & 183 & 4.63 & Energy production and conversion \\
$\mathrm{G}$ & 313 & 7.93 & Carbohydrate transport and metabolism \\
$\mathrm{E}$ & 328 & 8.31 & Amino acid transport and metabolism \\
$\mathrm{F}$ & 86 & 2.17 & Nucleotide transport and metabolism \\
$\mathrm{H}$ & 134 & 3.39 & Coenzyme transport and metabolism \\
$\mathrm{I}$ & 118 & 2.99 & Lipid transport and metabolism \\
$\mathrm{P}$ & 184 & 4.66 & Inorganic ion transport and metabolism \\
$\mathrm{Q}$ & 91 & 2.30 & Secondary metabolites biosynthesis, transport and catabolism \\
$\mathrm{R}$ & 443 & 11.22 & General function prediction only \\
$\mathrm{S}$ & 360 & 9.12 & Function unknown \\
$\mathrm{W}$ & 0 & 0 & Extracellular structures \\
$\mathrm{Y}$ & 0 & 0 & Nuclear structure \\
$\mathrm{Z}$ & 1 & 0.02 & Cytoskeleton \\
$\mathrm{-}$ & 762 & 19.31 & Not in COGs \\
\hline & & &
\end{tabular}

${ }^{a}$ The total is based on the total number of protein-coding genes in the genome

availability in the soil [47]. Regarding soils containing abundant ferric form $\left(\mathrm{Fe}^{3+}\right)$ which is poorly available to plants, the literature described bacteria producing siderophores with high specificity and affinity for iron, capable of binding, extracting and transporting iron near the plant roots [48]. B. subtilis PTA-271 genome also predicted the production of such siderophores, namely the catecholic siderophore 2,3-dihydroxybenzoate-glycine-threonine trimeric ester bacillibactin encoded by 5 genes ( $d h b A$ to $d h b F)$. Surfactants produced by beneficial bacteria also contribute to increase the availability of hydrophobic nutrients. In this sense, B. subtilis PTA-271 is suspected to produce surfactin (with $\operatorname{srfAA}$ to $\operatorname{srf} A D$ ), a powerful biosurfactant due to its amphiphilic nature that strongly anchor with lipid layers, interfering with the structure of biological membranes [49].
Plant root morphology is also described to impact nutrient uptake and thus plant growth due to the stimulation of lateral root formation and root hair formation [50, 51]. Plant hormones are key elements for root morphology changes. Some beneficial bacteria are also described to produce them [51]. Regarding B. subtilis PTA-271 genome, it predicts the trp group, described in literature to produce tryptophan as the main precursor of the auxin IAA (indole-3-acetic acid) [42]. The genome of B. subtilis PTA-271 also predicts genes such as $y v d D$ (Supplementary Table S2), linked in the literature to cytokinin synthesis which is known as a plant growth regulator (cell division, organogenesis) in combination with IAA. Gibberellins (GA) produced by some bacteria also affect the plant growth and survival [51]. Regarding the B. subtilis PTA-271 genome, it predicts ispD and GerC3_ 
$H e p T$, described in the literature to be respectively linked to 2-C-methyl-D-erythritol 4-phosphate (MEP) and geranylgeranyl diphosphate (GGPP) production, two successive precursors of GA and abscisic acid (ABA) synthesis in plants [52].

Genes described to encode for other plant growth regulators, namely polyamines (PAs), are also predicted in the genome of B. subtilis PTA-271. Among them: speA, speB, spe $G$ and speE are respectively described in literature to encode for putative ADC (arginine decarboxylase), agmatinase (leading to putrescine), then spermidineand spermine- synthases. Additionally, genes encoding for putative S-adenosyl-methionine (SAM) decarboxylase (speH) and SAM-methyltransferase (S19-40_00450) are predicted in B. subtilis PTA-271 genome, and these proteins are mentioned to complete PA synthesis from putrescine [53]. PAs are known to promote flowering and to play important roles in inducing cell division, promoting regeneration of plant tissues and cell cultures [54], as delaying senescence [55].

Volatile compounds (VOCs) produced by some beneficial rhizospheric bacteria have also been identified as elicitors promoting plant growth. Regarding B. subtilis PTA-271, its predicted genes encode putatively for (1) acetoin (acuA, acuC...) and (2) 2,3-butanediol (butA and butC) $[20,56]$. VOCs are especially reported to interact with plant hormones [57-59].

\section{Host induced defenses and microbiota preservation: assets for plant protection}

PLANT INDUCED DEFENSES upon biotic stress Host primed defenses during ISR are regulated by hormones, depending on either JA and ET signaling or SA signaling [7, 8, 10, 60]. Beneficial microorganisms may modulate the plant hormonal balance or directly elicit the plant defenses. Regarding the genome of $B$. subtilis PTA-271, the metK gene is predicted to encode for SAM synthase that would appear ISR-useful for plants which possess the complementary ET metabolic machinery $[53,55]$. SA is another hormone for which several genes encoding its metabolic pathways (from synthesis to hydrolysis) are predicted in B. subtilis PTA-271 genome, among which $p c h A$ putatively encoding for the salicylate biosynthesis isochorismate synthase.

Many elicitors also induce host immunity, coming from microorganisms (MAMPs, microbial associated molecular patterns) but also from the plant host (DAMPs, damageassociated molecular patterns). MAMPs can act from the external surface of a beneficial microorganism (flagellin) or result from a secretion outside or inside the host (surfactin, fengycin, VOCs, etc.) [58, 61-63]. Flagellin proteins are putatively encoded by the hag gene predicted in B. subtilis PTA-271 (Supplementary Table S1). The lipopeptides surfactin and fengycin are other elicitors of plant ISR putatively encoded by some genes predicted in the genome of
B. subtilis PTA-271 (srf and fen genes, respectively). VOCs produced by rhizospheric bacteria, as the 3-hydroxy 2butanone and acetoin which are putatively encoded by $B$. subtilis PTA-271 genome, are also well known to induce ISR [58]. Among VICs, the ubiquitous nitric oxide (NO) is another signal molecule [64]. Different genes related to NO metabolic pathways are predicted in B. subtilis PTA-271 genome, among which the gene nos putatively encoding for a NO synthase oxygenase. Exopolysaccharides (EPS) and lipopolysaccharides (LPS) are other elicitors reported in several Bacillus genera [9-14, 60]. Regarding the genome of B. subtilis PTA-271, it predicts several genes putatively encoding for EPS (S19-40_00800, S19-40_00870, S19-40_ 00999, S19-40_01009, S19-40_01427) and LPS (lptB, lapA, lap $B$ ), additionally to the other elicitors predicted to be encoded by B. subtilis PTA-271 genome (siderophores, flagella, N-acyl-L-homoserine lactone, etc.).

DAMPs are alternative elicitors produced by lytic enzymes (chitosan, glucans, etc.) of microorganisms (either beneficial or pathogenic) or plants [62]. Genes encoding for lytic enzymes are predicted in B. subtilis PTA-271 genome, such as those encoding for putative chitosanase and ß-glucanase (Supplementary Table S3). Many other genes are also predicted to encode for lytic enzymes in the B. subtilis PTA-271 spore cortex (Supplementary Table S4) for which the roles remain unclear.

PLANT INDUCED DEFENSES upon abiotic stress Some previously cited hormones are also useful for plant defense against abiotic stress, such as ABA and GA [8], of which precursors are predicted to be encoded by genes identified in the genome of B. subtilis PTA-271 (GerC3 $H e p T$, ispD). From GGPP, the kaurene pathway may lead to $\mathrm{GA}$, while the phytoene path may lead to ABA [52], and in the genome of B. subtilis PTA-271, yisP (a crtb KEGG gene) encodes for a putative 15-cis-phytoene/alltrans-phytoene synthase. ET is another useful hormone for plant defense against abiotic stress [8], and B. subtilis PTA-271 genome has genes identified to putatively produce SAM (metK). Altogether these data predict that $B$. subtilis PTA-271 genome may putatively encode for key precursors of phytohormones that may influence actively $\mathrm{ABA}$ and $\mathrm{ET}$ contents in plants. In plants, $\mathrm{ABA}, \mathrm{GA}$ and ET signaling pathways interfere altogether through different transcription factors (TF) or small proteins (GiD, DELLA, EIN, etc.) that physically interact $[65,66]$. In the genome of $B$. subtilis PTA-271, many genes are predicted to encode for sigma factors and many TF (Supplementary Table S2). It is noteworthy to understand that useful TF upon abiotic stress could also be useful upon biotic stress. The set of genes under common regulatory controls (operons) are also listed in the Supplementary Table S2.

PAs such as those predicted to be encoded by the genome of B. subtilis PTA-271 are also described to protect 
plant cells upon water deficit [67], temperature changes [68] and salinity [69].

MICROBIOTA quality and preservation As energy and carbon sources, plant root exudates (sugars, organic acids, amino acids, lipophilic compounds, etc.) would enable the selective recruitment of biosurfactant producers $[70,71]$. In return, these beneficial bacteria can facilitate the bioavailability of root exudates and biofilm formation, thus the colonization of host-plants by beneficial bacteria [49, 70, 72], maybe such as $B$. subtilis PTA-271 which is suspected to produce surfactin. SA was also shown to mediate changes in the composition of root exudates, then in the qualitative microorganism recruitment by plants [19]. Regarding the B. subtilis PTA-271 genome, some genes are also predicted to produce SA ( $p c h A)$, highlighting another key lever that putatively influence the composition of plant microbiome.

Beneficial microbial interactions can additionally depend on bacterial auto-inducers (AI) that are low-molecular weight signal molecules activating the interactive competences of a bacterium in a quorum-sensing (QS) dependent manner [73]. Among AI, the furanosyl-borate-diester (AI2 ) is described as universal for interspecies communication both in Gram-positive and Gram-negative bacteria [74]. Regarding B. subtilis PTA-271 genome, the predicted luxS gene putatively encodes for AI-2 production, while the predicted $E n t F$ and $A M 373$ putatively encode oligopeptides or auto-inducing peptide (AIP) precursors. AIP is another class of AI consisting of 5-34 amino acids residues and produced by Gram-positive bacteria for their intercellular communication [75].

When interacting with the environment, a microorganism must also remain metabolically active to exert beneficial effects. Upon biotic interactions, Bacillus species are exposed to host defenses that include reactive oxygen species (ROS) [76]. Regarding the system of sensing, protection and regulation of ROS in the genome of B. subtilis PTA271 , genes are predicted to putatively encode for resistance to hydroperoxide (ohrA, ohrB, ohrR). Upon abiotic stress, beneficial bacteria must survive dehydration, wounding, cold, heat or salinity that in turn lead to regulation of the water status. For this end, bacterial species can control their intracellular solute pools [77, 78]. Regarding the genome of B. subtilis PTA-271, genes predicted to encode for potassium uptake proteins (KtrA, KtrB) putatively enable survival in high salinity environments. Interestingly, the genome of B. subtilis PTA-271 also predicts genes to detoxify or resist compounds accumulating in the environment $[79,80]$, such as arsenite (arsR), organic pesticides or nitroaromatic compounds (sugE, qacC, $m h q R$, $m h q A$ ) among others (Supplementary Tables S2 and S5).

Upon extreme environmental conditions, some beneficial bacteria can sporulate, turning on endospore form
[1, 81]. Regarding the genome of B. subtilis PTA-271, several genes are predicted to be involved in the sporulation process (Supplementary Table S4): spo (sporulation control), ger (germination control), cot (endospore external layer) and $c w$ (spore cortex lytic enzymes), putatively enabling it to survive long lasting periods while preserving all beneficial strengths for plant profits.

\section{Direct confrontation with pathogens or aggressive molecules} Upon direct confrontation, Bacillus species also need to protect themselves against pathogen defenses. In addition to ROS protection, diverse transporters mediate antibiotic extrusion, whether specific to a substance or a group of substances. Regarding the genome of B. subtilis PTA-271, the specific transporters predicted would putatively confer it resistance towards: tetracyclin (tet $A$, tet $R$, tet $D)$, fosfomycin (fos $B)$, erythromycin ( $m s r A, m s r B)$, bacillibactin $(y m f D)$, bacitracin (BceA, BceB, BcrC), bleomycin (ble) and riboflavin (ribZ, $r f n T)$ for example. Among the non-specific transporters (or multidrug transporters) predicted in the genome of B. subtilis PTA-271 are: mepA, ebrA and ebrB; $y k k D$ and $y k k C$; $b m r A$ and $b m r 3$; emr $Y$, among others.

Bacillus species can additionally directly detoxify some pathogen aggressive molecules targeting plants, such as phytotoxins, by the mean of antitoxins or detoxifying enzymes such as transferases and CYP450s [82, 83]. In the genome of $B$. subtilis PTA-271, the main transferases predicted are glutathione-S-transferases GST, malonyltransferases MT, glucosyl-transferases GT and many others, while the main CYP450s predicted are monooxygenases and dioxygenases (Supplementary Table S5). Quenching enzymes constitute another lever for beneficial bacteria to directly target pathogen aggressive molecules, by preventing their QS-dependent production [8, 84]. Indeed, Bacillus species share aiiA gene encoding for $\mathrm{N}$ acetyl homoserine lactonase able to hydrolyze the lactone ring of the AHLs (Acyl-homoserine lactones) involved in the QS production of some pathogen virulent factors. The genome analysis of $B$. subtilis PTA-271 predicts such genes putatively encoding for quenching enzymes such as lactonases, $\beta$-lactamases, deaminases, deacetylases and other (de)acylases (Supplementary Table S6).

Polyketide synthases (PKS) are another type of transferases, namely acetyltransferases, described to produce plant beneficial molecules as microbicide for phytopathogens: the polyketides (PK) $[85,86]$. Regarding the genome of B. subtilis PTA-271, 15 genes are predicted to encode for putative PKS, many others for acetyltransferases or for enzymes sharing similar part of the PKS functions (Supplementary Table S7). According to antiSMASH 5.1.0, B. subtilis PTA271 genome predicts 11 secondary metabolites gene clusters, among which: 1 PKS cluster and 1 hybrid PKS-NRPS cluster (Supplementary Table S8). 
An extensive range of pathogen direct effectors are additionally produced by Bacillus spp., such as the RP (ribosomally synthesized peptides) and NRP (non-ribosomally synthesized peptides) antimicrobial molecules [20, 87]. Some of them are predicted as encoded by the genome of B. subtilis PTA-271, such as: Baillaene $(p k s D)$, subtilosin (sboA, albG, albE, albD, albB, albA) and bacilysin (bacE, $b a c F, b a c G)$ (Supplementary Table S3). Lipopeptides are other NRP antimicrobial molecules $[49,88]$, which encoding genes are predicted in the genome of $B$. subtilis PTA-271 to putatively produce the powerful antifungal substances fengycin and surfactin (Supplementary Table S3). Besides antibiotics and surfactants, bacterial siderophores can also directly alter pathogen fitness and aggressiveness, by depriving pathogen growth of iron while providing it for plant growth [89]. Regarding the genome of $B$. subtilis PTA-271, predicted genes putatively encode for the siderophore Bacillibactin (Supplementary Table S3). Lytic enzymes (CWDE) are other important feature of Bacillus spp. that can both alter pathogen survival and produce MAMPs [90]. Regarding the genome of $B$. subtilis PTA-271, several genes are predicted to encode for putative CWDE: 1 chitosanase (csn), $1 \beta$-glucanase (bglS), $1 \beta$-glucanase / cellulase (eglS) and about 80 proteases (Supplementary Table S3).

Besides these NRP and RP antimicrobial molecules, the genome of B. subtilis PTA-271 also predicts the genes $h c n C, a c u$ and but, putatively encoding for the volatile antimicrobial compounds: VIC (hydrogen cyanide, $\mathrm{HCN}$ ) and VOC (acetoin and 2,3-butanediol), respectively [8, 20, 56].

According to COG categories, $2.30 \%$ of $B$. subtilis PTA271 genome is predicted to be devoted to the production of secondary metabolites, considered as one of the most important features in biocontrol activities. AntiSMASH 5.1.0 predicts 11 secondary metabolites gene clusters in $B$. subtilis PTA-271 genome, among which 3 NRPS clusters and 2 RiPPs clusters (Supplementary Table S8).

\section{B. subtilis PTA-271 GENOME COMPARISON WITH OTHER GENOMES}

To understand the magnitude of the differences between B. subtilis PTA-271 and other Bacillus strains, the PTA-

Table 6 Comparative NCBI genome analysis of Bacillus subtilis PTA-271 with strains showing $\geq 99 \%$ of $16 \mathrm{~s}$ similarity

\begin{tabular}{|c|c|c|c|c|c|c|c|c|c|}
\hline & Strain & $\begin{array}{l}\text { Gb accession } \\
\text { number }\end{array}$ & Isolation source & Country & $\begin{array}{l}\text { Genome } \\
\text { size } \\
\text { (bp) } \\
\end{array}$ & $\begin{array}{l}\mathrm{G}+\mathrm{C} \\
\text { content } \\
(\%) \\
\end{array}$ & $\begin{array}{l}\begin{array}{l}\text { Protein- } \\
\text { coding } \\
\text { sequences }\end{array} \\
\end{array}$ & $\begin{array}{l}\text { tRNA } \\
\text { coding } \\
\text { genes }\end{array}$ & rRNA \\
\hline & Bacillus subtilis subsp. subtilis strain PTA-271 & - & $\begin{array}{l}\text { rhizosphere, roots, } \\
\text { leaves and stems } \\
\text { (Grapevine) }\end{array}$ & France & 4.002 & 43.8 & 3945 & 81 & 11 \\
\hline \multirow[t]{5}{*}{ Type-strains } & Bacillus subtilis 9407 & PISO01000016 & apple tree & $\begin{array}{l}\text { China } \\
\text { not } \\
\text { available/ }\end{array}$ & 4.19 & 43.4 & 4012 & 79 & 9 \\
\hline & Bacillus subtilis subsp. subtilis NCIB 3610 & СР034484 & not available/ unknown & unknown & 4.3 & 43.34 & 4390 & 86 & 30 \\
\hline & $\begin{array}{l}\text { Bacillus subtilis subsp. subtilis } 168 \\
\text { Bacillus amyloliquefaciens subsp. plantarum }\end{array}$ & СР019662 & soil & Germany & 4.22 & 43.5 & 4284 & 86 & 30 \\
\hline & FZB42 & СР000560 & soil (sugar beet) & Germany & 3.92 & 46.5 & 3687 & 89 & 31 \\
\hline & Bacillus velezensis KCTC 13012 & LHCC01000001 & river velez & spain & 4.04 & 46.3 & 3806 & 80 & 9 \\
\hline \multirow[t]{24}{*}{$\begin{array}{l}\text { Non type- } \\
\text { strains }\end{array}$} & Bacillus subtilis subsp. subtilis QB5413 & СР017313 & not available/ unknown & France & 4.22 & 42.7 & 5099 & 84 & 30 \\
\hline & Bacillus subtilis SRCM104005 & СР035164 & food & South Korea & 4.14 & 43.8 & 4106 & 86 & 30 \\
\hline & Bacillus subtilis $\mathrm{QB} 61$ & СР029461 & soil & China & 4.12 & 43.7 & 4086 & 85 & 28 \\
\hline & Bacillus subtilis subsp. subtilis QB5412 & СР017312 & not available/ unknown & France & 4.22 & 43.5 & 4252 & 86 & 30 \\
\hline & Bacillus subtilis SR1 & СP021985 & soil & India & 4.09 & 44.2 & 3911 & 83 & 30 \\
\hline & Bacillus subtilis SG6 & СР009796 & luffa & China & 4.08 & 43.8 & 4030 & 84 & 21 \\
\hline & Bacillus subtilis SRCM103773 & СР035397 & food & South Korea & 4.05 & 43.6 & 4113 & 86 & 30 \\
\hline & Bacillus subtilis PR10 & СР040528 & Tobacco rhizosphere soil & China & 4.07 & 43.8 & 3978 & 86 & 30 \\
\hline & Bacillus subtilis GQJK2 & СР020367 & rhizosphere & China & 4.07 & 43.8 & 3976 & 86 & 30 \\
\hline & Bacillus subtilis subsp. subtilis BS155 & CP029052 & marine sediment & China & 4.33 & 43.5 & 2718 & 86 & 30 \\
\hline & Bacillus subtilis SRCM103835 & СР035400 & food & South Korea & 4.14 & 43.8 & 4108 & 86 & 30 \\
\hline & Bacillus subtilis SRCM103837 & СР035401 & food & South Korea & 4.14 & 43.8 & 4113 & 86 & 30 \\
\hline & Bacillus subtilis SRCM103641 & СР035390 & food & South Korea & 4.11 & 43.7 & 4136 & 86 & 30 \\
\hline & Bacillus subtilis $\mathrm{H} 19$ & СР039935 & seawater & China & 4.06 & 43.9 & 4001 & 86 & 30 \\
\hline & Bacillus subtilis BS38 & СР017314 & soybean paste & South Korea & 4.01 & 43.6 & 3876 & 86 & 30 \\
\hline & Bacillus subtilis subsp. spizizenii SW83 & СР030925 & Turbinaria ornata & India & 3.98 & 43.8 & 3936 & 83 & 8 \\
\hline & Bacillus subtilis subsp. subtilisGFR-12 & СР032852 & Fermented soybean paste & South Korea & 4.2 & 43.3 & 4117 & 87 & 30 \\
\hline & Bacillus subtilis subsp. subtilis $2 \mathrm{KL} 1$ & CP032872 & Fermented soybean paste & South Korea & 4.2 & 43.3 & 4110 & 93 & 33 \\
\hline & Bacillus subtilis SRCM103886 & СР035162 & food & South Korea & 4.21 & 43.3 & 4121 & 87 & 30 \\
\hline & Bacillus subtilis subsp. subtilis $2 \mathrm{RL} 2-3$ & CP032857 & Fermented soybean paste & South Korea & 4.19 & 43.4 & 4083 & 87 & 33 \\
\hline & Bacillus subtilis SRCM103576 & CP035402 & food & South Korea & 4.01 & 43.5 & 3986 & 86 & 30 \\
\hline & Bacillus subtilis subsp. subtilis N4-2 & СР032867 & Natto & Japan & 4.12 & 43.5 & 4154 & 87 & 30 \\
\hline & Bacillus sp. M4U3P1 & $\mathrm{CP} 041372$ & Suaeda salsa & China & 4.12 & 43.5 & 4068 & 87 & 30 \\
\hline & Bacillus subtilis subsp. subtilis N3-1 & $\mathrm{CP} 032865$ & Natto & Japan & 4.12 & 43.5 & 4069 & 87 & 30 \\
\hline
\end{tabular}


271 genome has been compared to the complete genomes of 5 type-strains (B. subtilis NCIB 3610, B. subtilis 168, B. subtilis $9407, B$. amyloliquefaciens subsp. plantarum strain FZB42, and B. velezensis KTCT 13012) [91] and 32 nontype strains, represented in Table 6 . Among non-type strains showing $\geq 99 \%$ of the $16 \mathrm{~S}$ ribosomal gene similarity with PTA-271 are 31 distinct strains of B. subtilis and 1 Bacillus velezensis. For this genomic comparison, was used the GGDC 2.1 web server [92], the DSMZ phylogenomics pipeline to estimate DNA-DNA hybridization (DDH) [92], and the JSpecies WS web server to estimate the Average Nucleotide Identity (ANI) through pairwise comparisons [93]. The DDH value was estimated using the recommended formula (formula two) for draft genomes, at the GGDC website [94]. The ANI values were calculated using Ezbiocloud [95]. The whole data analysis enabled to obtain the intergenomic distances between genomes and their probability of belonging to the same species or subspecies. The general comparison of genomes is reported in Table 6, while the intergenomic distances (DDH estimate and ANI) are shown in Table 7.

Among the type strain genomes, the closest strain to B. subtilis PTA-271 was B. subtilis 9407, with a 0.0104 distance, a DDH estimate of $91.60 \%$, and an ANIm of 99.02\%. As expected, the most distant strain was $B$. velezensis KTCT 13012, with a 0.2268 distance, a DDH estimate of $19.40 \%$ and a $0 \%$ probability of being the same species, corroborated with an ANIm percentage of $77.02 \%$. Concerning the non-type strain genomes, the closer strains to PTA-271 were B. subtilis QB5413, B. subtilis SRCM 104005, and B. subtilis QB61 with distances of $0.0112,0.0119$ and 0.0119 respectively, and DDH estimates of $90.90,90.20$ and $90.20 \%$ respectively. The most distant strain was B. velezensis strain ATR2, with a distance of 0.2144 and a DDH estimate of $20.50 \%$ corroborated with an ANIm percentage of $77.1 \%$. The most distant B. subtilis strain to PTA-271 was B. subtilis

Table 7 Comparative genome distances analysis with other strains, using DNA-DNA hybridization and average nucleotide identities

\begin{tabular}{|c|c|c|c|c|c|c|c|c|c|}
\hline \multirow{2}{*}{\multicolumn{2}{|c|}{ Strains }} & \multirow{2}{*}{$\begin{array}{l}\text { Gb accession } \\
\text { number }\end{array}$} & \multicolumn{5}{|c|}{ DNA-DNA hybridization (DDH method) } & \multicolumn{2}{|c|}{$\begin{array}{c}\text { Average } \\
\text { nucleotide } \\
\text { identities } \\
\text { (ANIm) }\end{array}$} \\
\hline & & & Distance & $\begin{array}{c}\text { DDH } \\
\text { estimate }\end{array}$ & $\begin{array}{c}\text { Probability that } \\
\text { DDH } \\
>70 \% \text { (same } \\
\text { species) }\end{array}$ & $\begin{array}{c}\text { Probability that } \\
\text { DDH } \\
>79 \% \text { (same } \\
\text { subspecies) } \\
\end{array}$ & $\begin{array}{l}\text { Difference } \\
\text { in } \\
\% \mathbf{G}+\mathbf{C}\end{array}$ & $\underset{(\%)}{\text { ANIm }}$ & $\begin{array}{c}\text { Aligned } \\
\text { (bp) }\end{array}$ \\
\hline \multirow{5}{*}{ Type-strains } & Bacillus subtilis 9407 & PISO01000016 & 0.0104 & $91.60 \%$ & $96.29 \%$ & $67.69 \%$ & 0.56 & 99.02 & $1,456,961$ \\
\hline & Bacillus subtilis subsp. subtilis NCIB 3610 & CP034484 & 0.0121 & $90.00 \%$ & $95.80 \%$ & $65.28 \%$ & 0.27 & 98.88 & $2,509,972$ \\
\hline & Bacillus subtilis subsp. subtilis 168 & CP019662 & 0.0122 & $90.00 \%$ & $95.78 \%$ & $65.19 \%$ & 0.27 & 98.87 & $2,962,217$ \\
\hline & Bacillus amyloliquefaciens subsp. plantarum FZB42 & CP000560 & 0.2144 & $20.50 \%$ & $0.00 \%$ & $0.00 \%$ & 2.69 & 77.1 & $1,854,058$ \\
\hline & Bacillus velezensis KCTC 13012 & LHCC01000001 & 0.2268 & $19.40 \%$ & $0.00 \%$ & $0.00 \%$ & 2.84 & 77.02 & 437,224 \\
\hline \multirow{21}{*}{$\begin{array}{l}\text { Non type- } \\
\text { strains }\end{array}$} & Bacillus subtilis subsp. Subtilis QB5413 & CP017313 & 0.0112 & $90.90 \%$ & $96.08 \%$ & $66.63 \%$ & 1.05 & 98.76 & $2,529,290$ \\
\hline & Bacillus subtilis SRCM104005 & CP035164 & 0.0119 & $90.20 \%$ & $95.87 \%$ & $65.63 \%$ & 0.00 & 98.84 & $2,941,570$ \\
\hline & Bacillus subtilis QB61 & СР029461 & 0.0119 & $90.20 \%$ & $95.85 \%$ & $65.52 \%$ & 0.04 & 98.82 & $3,023,981$ \\
\hline & Bacillus subtilis subsp. subtilis QB5412 & CP017312 & 0.0122 & $89.90 \%$ & $95.78 \%$ & $65.17 \%$ & 0.27 & 98.85 & $2,985,990$ \\
\hline & Bacillus subtilis SR1 & CP021985 & 0.0124 & $89.70 \%$ & $95.70 \%$ & $64.82 \%$ & 0.24 & 98.86 & $2,881,899$ \\
\hline & Bacillus subtilis SG6 & CP009796 & 0.0124 & $89.70 \%$ & $95.70 \%$ & $64.83 \%$ & 0.05 & 98.81 & $2,968,883$ \\
\hline & Bacillus subtilis SRCM103773 & CP035397 & 0.0126 & $89.50 \%$ & $95.63 \%$ & $64.50 \%$ & 0.16 & 98.81 & $2,633,309$ \\
\hline & Bacillus subtilis PR10 & CP040528 & 0.0129 & $89.30 \%$ & $95.56 \%$ & $64.15 \%$ & 0.01 & 98.77 & $2,648,038$ \\
\hline & Bacillus subtilis GQJK2 & CP020367 & 0.0129 & $89.30 \%$ & $95.55 \%$ & $64.14 \%$ & 0.01 & 98.79 & $2,856,573$ \\
\hline & Bacillus subtilis subsp. subtilis BS155 & CP029052 & 0.0131 & $89.10 \%$ & $95.49 \%$ & $63.83 \%$ & 0.29 & 98.69 & $2,805,710$ \\
\hline & Bacillus subtilis SRCM103835 & CP035400 & 0.0132 & $89.00 \%$ & $95.44 \%$ & $63.61 \%$ & 0.02 & 98.75 & $2,640,533$ \\
\hline & Bacillus subtilis SRCM103837 & CP035401 & 0.0132 & $89.00 \%$ & $95.44 \%$ & $63.61 \%$ & 0.02 & 98.76 & $2,637,514$ \\
\hline & Bacillus subtilis SRCM103641 & CP035390 & 0.0137 & $\mathbf{8 8 . 6 0 \%}$ & $95.29 \%$ & $62.96 \%$ & 0.07 & 98.67 & $2,561,457$ \\
\hline & Bacillus subtilis $\mathrm{H} 19$ & CP039935 & 0.0144 & $88.00 \%$ & $95.05 \%$ & $61.95 \%$ & 0.11 & 98.62 & $2,750,901$ \\
\hline & Bacillus subtilis BS38 & CP017314 & 0.0149 & $87.40 \%$ & $94.84 \%$ & $61.09 \%$ & 0.19 & 98.52 & $2,702,006$ \\
\hline & Bacillus subtilis subsp. spizizenii SW83 & CP030925 & 0.0152 & $87.20 \%$ & $94.73 \%$ & $60.64 \%$ & 0.02 & 98.56 & $2,801,320$ \\
\hline & Bacillus subtilis subsp. subtilisGFR-12 & CP032852 & 0.0153 & $87.10 \%$ & $94.69 \%$ & $60.50 \%$ & 0.47 & 98.49 & $2,649,573$ \\
\hline & Bacillus subtilis subsp. subtilis $2 \mathrm{KL} 1$ & CP032872 & 0.0153 & $87.10 \%$ & $94.69 \%$ & $60.47 \%$ & 0.43 & 98.48 & $2,636,663$ \\
\hline & Bacillus subtilis SRCM103886 & CP035162 & 0.0153 & $87.10 \%$ & $94.68 \%$ & $60.45 \%$ & 0.48 & 98.49 & $2,651,166$ \\
\hline & Bacillus subtilis subsp. subtilis $2 \mathrm{RL} 2-3$ & CP032857 & 0.0153 & $87.10 \%$ & $94.68 \%$ & $60.44 \%$ & 0.43 & 98.50 & $2,597,779$ \\
\hline & Bacillus subtilis SRCM103576 & CP035402 & 0.0155 & $87.00 \%$ & $94.64 \%$ & $60.28 \%$ & 0.29 & 98.51 & $2,578,601$ \\
\hline \multirow{10}{*}{$\begin{array}{l}\text { Non type- } \\
\text { strains }\end{array}$} & Bacillus subtilis subsp. subtilis N4-2 & CP032867 & 0.0155 & $86.90 \%$ & $94.62 \%$ & $60.21 \%$ & 0.31 & 98.52 & $2,684,907$ \\
\hline & Bacillus sp. M4U3P1 & CP041372 & 0.0155 & $86.90 \%$ & $94.62 \%$ & $60.21 \%$ & 0.32 & 98.51 & $2,595,536$ \\
\hline & Bacillus subtilis subsp. subtilis N3-1 & CP032865 & 0.0155 & $86.90 \%$ & $94.62 \%$ & $60.20 \%$ & 0.31 & 98.54 & $2,616,955$ \\
\hline & Bacillus subtilis subsp. subtilis N2-2 & CP032863 & 0.0155 & $86.90 \%$ & $94.62 \%$ & $60.20 \%$ & 0.31 & 98.48 & $2,667,845$ \\
\hline & Bacillus subtilis subsp. subtilis N1-1 & CP032861 & 0.0155 & $86.90 \%$ & $94.62 \%$ & $60.19 \%$ & 0.29 & 98.56 & $2,473,375$ \\
\hline & Bacillus subtilis ATCC 21228 & CP020023 & 0.0156 & $86.90 \%$ & $94.60 \%$ & $60.12 \%$ & 0.33 & 98.53 & $2,668,973$ \\
\hline & Bacillus subtilis subsp. subtilis MH-1 & CP032853 & 0.0158 & $86.60 \%$ & $98.80 \%$ & $77.62 \%$ & 0.51 & $\mathbf{9 8 . 4 4}$ & $2,611,384$ \\
\hline & Bacillus subtilis SX01705 & CP022287 & 0.0175 & $85.10 \%$ & $93.79 \%$ & $57.14 \%$ & 0.08 & 98.31 & $2,686,386$ \\
\hline & Bacillus subtilis subsp. subtilis RO-NN-1 & СР002906 & 0.0203 & $82.60 \%$ & $92.41 \%$ & $52.68 \%$ & 0.09 & 98.04 & $2,857,714$ \\
\hline & Bacillus velezensis strain ATR2 & NZ_CP018133 & 0.2144 & $20.50 \%$ & $0 \%$ & $0 \%$ & 2.69 & 77.1 & $1,854,058$ \\
\hline
\end{tabular}


subsp. subtilis $\mathrm{RO}-\mathrm{NN}-1$ with a distance of 0.203 and a DDH of $82.60 \%$.

\section{Conclusion}

With a genome size of $4,001,755$ bp containing $97.69 \%$ of protein encoding genes, the draft genome of B. subtilis PTA-271 highlights all the qualities of a promising plant beneficial microorganism. The most relevant predicted genes encode for: (1) a functional swarming motility system highlighting advantageous colonizing capacity of host and a strong interacting capacity within plant microbiota; (2) a strong survival capacity, due to sporulation but also to complex detoxifying systems, auto-inducing metabolic paths and recruiting capacities for adding microbiota values; and (3) the delivery of many bioactive substances (hormones, elicitors, effectors and quenchers, siderophores and lytic enzymes, etc.), facilitating the stimulation of plant growth or defenses, or else, disturbing pathogen fitness or aggressiveness. Interestingly, the putative capacity of B. subtilis PTA271 to produce a wide range of phytohormone analogous (SA, ET precursor, ABA etc.), as well as diverse direct effectors and lytic enzymes against plant pathogens, highlight a significant potential for biocontrol strategies. Altogether, the plurality of the biomolecules putatively encoded by the genome of B. subtilis PTA-271 PTA-271 are putative strengths to impact both biochemical conditions, species ratios and their interactions, predicting an ability to combat a broad spectrum of plant pathogens such as grapevine trunk disease [3].

\section{Supplementary Information}

The online version contains supplementary material available at https://doi. org/10.1186/s40793-021-00372-3.

Additional file 1: Table S1. Bacillus subtilis PTA-271 encoding genes for motility, adhesion and plant root colonizing capacity.

Additional file 2: Table S2. Bacillus subtilis PTA-271 encoding genes for some Transcriptional regulators and Operons.

Additional file 3: Table S3. Bacillus subtilis PTA-271 encoding genes for antimicrobial molecules, other effectors and lytic enzymes.

Additional file 4: Table S4. Bacillus subtilis PTA-271 encoding genes for sporulation.

Additional file 5: Table S5. Bacillus subtilis PTA-271 encoding genes for some CYP450 and for Transferases.

Additional file 6: Table S6. Bacillus subtilis PTA-271 encoding genes for lactonases, $\beta$-lactamases, deaminases, deacetylases.

Additional file 7: Table S7. Bacillus subtilis PTA-271 encoding genes for PKS and other acetyltransferases.

Additional file 8: Table S8. Anti-SMASH 5.1.0 prediction of gene clusters responsible for secondary metabolite production in Bacillus subtilis PTA-271.

\section{Abbreviations}

ABA: abscisic acid; DAMPs: damage-associated molecular patterns; EPS: exopolysaccharides; ET: ethylene; GTD: grapevine trunk diseases; ISR: induced systemic resistance; JA: jasmonic acid; LPS: lipopolysaccharides;
MAMPs: microbial associated molecular patterns; NO: nitric oxide; NRP: nonribosomally synthesized peptides; PA: polyamines; PK: polyketides; RP: ribosomally synthesized antimicrobial peptides; RiPP: post-translationally modified RP; ROS: reactive oxygen species; SA: salicylic acid; ViC: inorganic volatile compound; VOC: organic volatile compound

\section{Acknowledgements}

We are grateful to Laëtitia Parent for her technical assistance. We are grateful to the Region GRAND-EST France and the City of GRAND-REIMS France for the PhD Grant financial support and to BELCHIM Crop Protection France for the financial support to functioning.

\section{Authors' contributions}

All authors contributed to writing and revising the manuscript. The author(s) read and approved the final manuscript.

\section{Funding}

This work was supported by a French Grant from the Region GRAND-EST France and the City of GRAND-REIMS France through the BIOVIGNE PhD program, which functioning is supported by BELCHIM Crop Protection France.

\section{Availability of data and materials}

The whole genome shotgun project has been deposited at DDBJ/ENA/ GenBank under the accession JACERQ000000000. The version described in this paper is version JACERQ000000000 and all related information is represented in Table 3.

\section{Ethics approval and consent to participate}

Not applicable.

\section{Consent for publication}

All authors approved the final version and consent for publication.

\section{Competing interests}

The authors declare that they have no competing interests.

\section{Author details}

'SFR Condorcet - FR CNRS 3417, University of Reims Champagne-Ardenne, Induced Resistance and Plant Bioprotection (RIBP) - EA 4707, BP1039, Cedex 2, F-51687 Reims, France. ${ }^{2}$ UC-Biotech_CNC, Biocant Park, Biotechnology Innovation Center, P-3060-197 Cantanhede, Portugal.

Received: 26 July 2020 Accepted: 7 January 2021

Published online: 29 January 2021

\section{References}

1. Nicholson WL, Munakata N, Horneck G, Melosh HJ, Setlow P. Resistance of Bacillus endospores to extreme terrestrial and extraterrestrial environments. Microbiol Mol Biol Rev. 2000;64(3):548-72.

2. Borriss R. Use of plant-associated Bacillus strains as biofertilizers and biocontrol agents in agriculture. Bacteria in agrobiology: plant growth responses. In: Maheshwari DK, editor. Bacteria in agrobiology: plant growth responses. Berlin Heidelberg: Springer-Verlag; 2011. p. 41-76. https://doi.org/ 10.1007/978-3-642-20332-9_3.

3. Trotel-Aziz P, Abou-Mansour E, Courteaux B, Rabenoelina F, Clément C, Fontaine F, et al. Bacillus subtilis PTA-271 counteracts Botryosphaeria dieback in grapevine, triggering immune responses and detoxification of fungal phytotoxins. Front Plant Sci. 2019;10:25.

4. Trotel-Aziz P, Couderchet M, Biagianti S, Aziz A. Characterization of new bacterial biocontrol agents Acinetobacter, Bacillus, Pantoea and Pseudomonas spp. mediating grapevine resistance against Botrytis cinerea. Environ. Exp. Bot. 2008;64(1):21-32.

5. Magnin-Robert M, Trotel-Aziz P, Quantinet D, Biagianti S, Aziz A. Biological control of Botrytis cinerea by selected grapevine-associated bacteria and stimulation of chitinase and $\beta-1,3$ glucanase activities under field conditions. Eur J Plant Pathol. 2007;118(1):43-57.

6. Wang $X Q$, Zhao DL, Shen LL, Jing CL, Zhang CS. Application and mechanisms of Bacillus subtilis in biological control of plant disease. In: Meena VS, editor. Role of rhizospheric microbes in soil. Singapore Pte Ltd: Springer Nature; 2018. p. 225-50. 
7. Pieterse CM, Leon-Reyes A, Van der Ent S, Van Wees SC. Networking by small-molecule hormones in plant immunity. Nat Chem Biol. 2009; 5(5):308-16

8. Pacifico D, Squartini A, Crucitti D, Barizza E, Lo Schiavo F, Muresu R, Carimi F, Zottini M. The role of the Endophytic microbiome in the grapevine response to environmental triggers. Front Plant Sci. 2019;10:1256.

9. Van Loon L, Bakker P, Pieterse C. Systemic resistance induced by rhizosphere bacteria. Annu Rev Phytopathol. 1998;36(1):453-83.

10. Pieterse CM, Zamioudis C, Berendsen RL, Weller DM, Van Wees SC, Bakker PA. Induced systemic resistance by beneficial microbes. Annu Rev Phytopathol. 2014;52:347-75.

11. Kloepper JW, Ryu C-M, Zhang S. Induced systemic resistance and promotion of plant growth by Bacillus spp. Phytopathology. 2004;94(11):1259-66.

12. Zamioudis C, Korteland J, Van Pelt JA, van Hamersveld M, Dombrowski N, Bai $Y$, et al. Rhizobacterial volatiles and photosynthesis-related signals coordinate MYB 72 expression in Arabidopsis roots during onset of induced systemic resistance and iron-deficiency responses. Plant J. 2015;84(2):309-22

13. Akram W, Anjum T, Ali B. Searching ISR determinant/s from Bacillus subtilis IAGS174 against Fusarium wilt of tomato. BioControl. 2015:60(2):271-80.

14. Audrain B, Farag MA, Ryu C-M, Ghigo J-M. Role of bacterial volatile compounds in bacterial biology. FEMS Microbiol Rev. 2015;39(2):222-33.

15. Glick BR. Bacteria with ACC deaminase can promote plant growth and help to feed the world. Microbiol Res. 2014;169(1):30-9.

16. Xie S-S, Wu H-J, Zang H-Y, Wu L-M, Zhu Q-Q, Gao X-W. Plant growth promotion by spermidine-producing Bacillus subtilis OKB105. Mol PlantMicrobe Interact. 2014;27(7):655-63.

17. Sharifi R, Ryu C-M. Revisiting bacterial volatile-mediated plant growth promotion: lessons from the past and objectives for the future. Ann Bot. 2018;122(3):349-58.

18. Tyagi S, Mulla SI, Lee K-J, Chae J-C, Shukla P. VOCs-mediated hormonal signaling and crosstalk with plant growth promoting microbes. Crit Rev Biotechnol. 2018;38(8):1277-96.

19. Huang X-F, Chaparro JM, Reardon KF, Zhang R, Shen Q, Vivanco JM. Rhizosphere interactions: root exudates, microbes, and microbial communities. Botany. 2014;92(4):267-75.

20. Caulier S, Nannan C, Gillis A, Licciardi F, Bragard C, Mahillon J. Overview of the antimicrobial compounds produced by members of the Bacillus subtilis group. Front Microbiol. 2019;10:302

21. Lopes R, Tsui S, Gonçalves PJ, de Queiroz MV. A look into a multifunctional toolbox: endophytic Bacillus species provide broad and underexploited benefits for plants. World J Microbiol Biotechnol 2018;34(7):94. https://doi. org/https://doi.org/10.1007/s11274-018-2479-7.

22. Mondello V, Songy A, Battiston E, Pinto C, Coppin C, Trotel-Aziz P, et al. Grapevine trunk diseases: a review of fifteen years of trials for their control with chemicals and biocontrol agents. Plant Dis. 2018;102(7): 1189-217.

23. Field D, Garrity G, Gray T, Morrison N, Selengut J, Sterk P, et al. The minimum information about a genome sequence (MIGS) specification. Nat Biotechnol. 2008;26(5):541-7.

24. Bolger AM, Lohse M, Usadel B. Trimmomatic: a flexible trimmer for Illumina sequence data. Bioinformatics. 2014;30(15):2114-20.

25. Bankevich A, Nurk S, Antipov D, Gurevich AA, Dvorkin M, Kulikov AS, et al. SPAdes: a new genome assembly algorithm and its applications to singlecell sequencing. J Comput Biol. 2012;19(5):455-77.

26. Gurevich A, Saveliev V, Vyahhi N, Tesler G. QUAST: quality assessment tool for genome assemblies. Bioinformatics. 2013;29(8):1072-5.

27. Parks DH, Imelfort M, Skennerton CT, Hugenholtz P, Tyson GW. CheckM: assessing the quality of microbial genomes recovered from isolates, single cells, and metagenomes. Genome Res. 2015;25(7):1043-55.

28. Hyatt $D$, Chen $G$, Locascio P, Land M, Larimer F, Hauser L. BMC bioinformatics [electronic resource]. BMC Bioinform. 2010;11:119.

29. Seemann T. Prokka: rapid prokaryotic genome annotation. Bioinformatics. 2014;30(14):2068-9.

30. Pedruzzi I, Rivoire C, Auchincloss AH, Coudert E, Keller G, De Castro E, et al, HAMAP in 2015: updates to the protein family classification and annotation system. Nucleic Acids Res. 2015;43(1):1064-70.

31. Haft DH, Selengut JD, White O. The TIGRFAMs database of protein families Nucleic Acids Res. 2003;31(1):371-3.

32. Finn RD, Coggill P, Eberhardt RY, Eddy SR, Mistry J, Mitchell AL, et al. The Pfam protein families database: towards a more sustainable future. Nucleic Acids Res. 2016:44(1):279-85.
33. Kanehisa M, Sato Y, Furumichi M, Morishima K, Tanabe M. New approach for understanding genome variations in KEGG. Nucleic Acids Res. 2019:47(1):590-5.

34. Rawlings ND, Barrett AJ, Finn R. Twenty years of the MEROPS database of proteolytic enzymes, their substrates and inhibitors. Nucleic Acids Res. 2016; 44(1):343-50.

35. Yin $Y$, Mao $X$, Yang J, Chen $X$, Mao F, Xu Y. dbCAN: a web resource for automated carbohydrate-active enzyme annotation. Nucleic Acids Res. 2012; 40(1):445-51.

36. Stothard $P$, Wishart DS. Circular genome visualization and exploration using CGView. Bioinformatics. 2005;21(4):537-9.

37. Henrichsen J. Bacterial surface translocation: a survey and a classification. Bacteriol Rev. 1972;36(4):478.

38. Davey ME, O'toole GA. Microbial biofilms: from ecology to molecular genetics. Microbiol Mol Biol Rev. 2000;64(4):847-67.

39. Hamon MA, Lazazzera BA. The sporulation transcription factor Spo0A is required for biofilm development in Bacillus subtilis. Mol Microbiol. 2001; 42(5):1199-209.

40. Santoyo G, Moreno-Hagelsieb G, del Carmen O-MM, Glick BR. Plant growthpromoting bacterial endophytes. Microbiol Res. 2016;183:92-9.

41. Lugtenberg B, Kamilova F. Plant-growth-promoting rhizobacteria. Annu Rev Microbiol. 2009:63:541-56.

42. Glick BR. Plant growth-promoting bacteria: mechanisms and applications. Scientifica. 2012;2012(5):963401. http://dx.doi.org/https://doi.org/10.6064/ 2012/963401

43. Zaidi A, Khan MS, Rizvi A, Saif S, Ahmad B, Shahid M. Role of phosphatesolubilizing bacteria in legume improvement. In: Zaidi A, Khan M, Musarrat (eds) Microbes for Legume Improvement Springer-Verlag, Wien. 2010;175197. DOl https://doi.org/10.1007/978-3-211-99753-6_11

44. Van Schie B, De Mooy O, Linton J, Van Dijken J, Kuenen J. PQQ-dependent production of gluconic acid by Acinetobacter. Agrobacterium and Rhizobium species Microbiology. 1987;133(4):867-75.

45. Toyama H, Chistoserdova L, Lidstrom ME. Sequence analysis of pqq genes required for biosynthesis of pyrroloquinoline quinone in Methylobacterium extorquens AM1 and the purification of a biosynthetic intermediate. Microbiology. 1997;143(2):595-602.

46. Konietzny U, Greiner R. Bacterial phytase: potential application, in vivo function and regulation of its synthesis. Braz J Microbiol. 2004;35(1-2):12-8.

47. Andrews SC, Robinson AK, Rodríguez-Quiñones F. Bacterial iron homeostasis. FEMS Microbiol Rev. 2003;27(2-3):215-37.

48. Powell P, Szaniszlo P, Cline G, Reid C. Hydroxamate siderophores in the iron nutrition of plants. J Plant Nutr. 1982;5(4-7):653-73.

49. Ongena M, Jacques P. Bacillus lipopeptides: versatile weapons for plant disease biocontrol. Trends Microbiol. 2008;16(3):115-25.

50. Bohn-Courseau I. Auxin: a major regulator of organogenesis. C R Biol. 2010; 333(4):290-6.

51. Bottini R, Cassán F, Piccoli P. Gibberellin production by bacteria and its involvement in plant growth promotion and yield increase. Appl Microbiol Biotechnol. 2004;65(5):497-503

52. Rodríguez-Gacio MC, Matilla-Vázquez MA, Matilla AJ. Seed dormancy and ABA signaling: the breakthrough goes on. Plant Signal Behav. 2009;4(11):1035-48.

53. Aziz A, Martin-Tanguy J, Larher F. Plasticity of polyamine metabolism associated with high osmotic stress in rape leaf discs and with ethylene treatment. Plant Growth Regul. 1997;21(2):153-63.

54. Chen D, Shao Q, Yin L, Younis A, Zheng B. Polyamine function in plants: metabolism, regulation on development, and roles in abiotic stress responses. Front Plant Sci. 2019;9:1945. https://doi.org/10.3389/ fpls.2018.01945.

55. Pandey S, Ranade S, Nagar P, Kumar N. Role of polyamines and ethylene as modulators of plant senescence. J Biosci. 2000;25(3):291-9.

56. Bitas V, Kim H-S, Bennett JW, Kang S. Sniffing on microbes: diverse roles of microbial volatile organic compounds in plant health. Mol Plant-Microbe Interact. 2013;26(8):835-43.

57. Zhang H, Kim M-S, Krishnamachari V, Payton P, Sun Y, Grimson M F, et al. Rhizobacterial volatile emissions regulate auxin homeostasis and cell expansion in Arabidopsis. Planta. 2007;226(4):839

58. Ortíz-Castro R, Contreras-Cornejo HA, Macías-Rodríguez L, López-Bucio J. The role of microbial signals in plant growth and development. Plant Signal Behav. 2009:4(8):701-12.

59. Xie $X$, Zhang $H$, Pare P. Sustained growth promotion in Arabidopsis with long-term exposure to the beneficial soil bacterium Bacillus subtilis (GB03) Plant Signal Behav. 2009;4(10):948-53. 
60. Villena J, Kitazawa H, Van Wees S, Pieterse CM, Takahashi H. Receptors and signaling pathways for recognition of bacteria in livestock and crops: prospects for beneficial microbes in healthy growth strategies. Front Immunol. 2018:9:2223.

61. Felix G, Duran JD, Volko S, Boller T. Plants have a sensitive perception system for the most conserved domain of bacterial flagellin. Plant J. 1999; 18(3):265-76.

62. Heloir MC, Adrain M, Brulé D, Claverie M, Cordelier S, Daire X, Dorey S, Gauthier A, Lemaitre-Guillier C, Negrel J, Trdá L, Trouvelot S, Vandelle E, Poinssot B. Recognition of elicitors in grapevine: from MAMP and DAMP perception to induced resistance. Front Plant Sci. 2019;10:1117.

63. Ongena M, Jourdan E, Adam A, Paquot M, Brans A, Joris B, et al. Surfactin and fengycin lipopeptides of Bacillus subtilis as elicitors of induced systemic resistance in plants. Environ Microbiol. 2007;9(4):1084-90

64. Sánchez-Vicente I, Fernández-Espinosa MG, Lorenzo O. Nitric oxide molecular targets: reprogramming plant development upon stress. J Exp Bot. 2019;70(17):4441-60

65. Liu $X$, Hou $X$. Antagonistic regulation of $A B A$ and $G A$ in metabolism and signaling pathways. Front Plant Sci. 2018;9:251.

66. Zentella R, Zhang Z-L, Park M, Thomas SG, Endo A, Murase K, et al. Global analysis of DELLA direct targets in early gibberellin signaling in Arabidopsis. Plant Cell. 2007;19(10):3037-57.

67. Ebeed HT, Hassan NM, Aljarani AM. Exogenous applications of polyamines modulate drought responses in wheat through osmolytes accumulation, increasing free polyamine levels and regulation of polyamine biosynthetic genes. Plant Physiol Biochem. 2017;118:438-48.

68. Tian J, Wang L-P, Yang Y-J, Sun J, Guo S-R. Exogenous spermidine alleviates the oxidative damage in cucumber seedlings subjected to high temperatures. J Am Soc Hortic Sci. 2012;137(1):11-9.

69. Saha J, Brauer EK, Sengupta A, Popescu SC, Gupta K, Gupta B. Polyamines as redox homeostasis regulators during salt stress in plants. Front Environ Sci. 2015;3:21.

70. Koo BJ, Adriano DC, Bolan NS, Barton CD. Root exudates and microorganisms. In: Hillel D, editor. Encyclopedia of soils in the environment. New York: Academic Press, USA; 2005. p. 421-8.

71. Siciliano SD, Germida JJ. Mechanisms of phytoremediation: biochemical and ecological interactions between plants and bacteria. Environ Rev. 1998:6:65-79.

72. Bais HP, Fall R, Vivanco JM. Biocontrol of Bacillus subtilis against infection of Arabidopsis roots by Pseudomonas syringae is facilitated by biofilm formation and surfactin production. Plant Physiol. 2004;134(1):307-19.

73. Newton J, Fray R. Integration of environmental and host-derived signals with quorum sensing during plant-microbe interactions. Cell Microbiol. 2004;6(3):213-24

74. Duanis-Assaf D, Steinberg D, Chai Y, Shemesh M. The LuxS based quorum sensing governs lactose induced biofilm formation by Bacillus subtilis. Front Microbiol. 2016;6:1517.

75. Verbeke F, De Craemer S, Debunne N, Janssens Y, Wynendaele E, Van de Wiele $C$, et al. Peptides as quorum sensing molecules: measurement techniques and obtained levels in vitro and in vivo. Front Neurosci. 2017;11:183.

76. Sukchawalit R, Loprasert S, Atichartpongkul S, Mongkolsuk S. Complex regulation of the organic Hydroperoxide resistance gene (ohr) from XanthomonasInvolves OhrR, a novel organic peroxide-inducible negative regulator, and posttranscriptional modifications. J Bacteriol. 2001;83(15): 4405-12.

77. Booth IR, Louis P. Managing hypoosmotic stress: aquaporins and medianosensitive channels in Escherichia coli. Curr Opin Microbiol. 1999;2(2): 166-9.

78. Levina N, Tötemeyer S, Stokes NR, Louis P, Jones MA, Booth IR. Protection of Escherichia coli cells against extreme turgor by activation of MscS and MscL mechanosensitive channels: identification of genes required for MscS activity. EMBO J. 1999;18(7):1730-7.

79. Sato T, Kobayashi Y. The ars operon in the skinElement of Bacillus subtilis confers resistance to arsenate and Arsenite. J Bacteriol. 1998;180(7):1655-61.

80. Vaillancourt FH, Bolin JT, Eltis LD. The ins and outs of ring-cleaving dioxygenases. Crit Rev Biochem Mol Biol. 2006;41(4):241-67.

81. Errington J. Bacillus subtilis sporulation: regulation of gene expression and control of morphogenesis. Microbiol Rev. 1993:57(1):1-33.

82. Karlovsky P. Biological detoxification of fungal toxins and its use in plant breeding, feed and food production. Nat Toxins. 1999:7:1-23.
83. Lyagin I, Efremenko E. Enzymes for detoxification of various mycotoxins: origins and mechanisms of catalytic actions. Molecules. 2019;24:2362.

84. Chen F, Gao Y, Chen X, Yu Z, Li X. Quorum quenching enzymes and their application in degrading signal molecules to block quorum sensingdependent infection. Int J Mol Sci. 2013;14(9):17477-500.

85. Olishevska S, Nickzad A, Déziel E. Bacillus and Paenibacillus secreted polyketides and peptides involved in controlling human and plant pathogens. Appl Microbiol Biotechnol. 2019;103(3):1189-215.

86. Cane DE, Walsh CT, Khosla C. Harnessing the biosynthetic code: combinations, permutations, and mutations. Science. 1998;282(5386):63-8

87. Yu X, Ai C, Xin L, Zhou G. The siderophore-producing bacterium, Bacillus subtilis CAS15, has a biocontrol effect on Fusarium wilt and promotes the growth of pepper. Eur J Soil Biol. 2011;47(2):138-45.

88. Finking R, Marahiel MA. Biosynthesis of nonribosomal peptides. Annu Rev Microbiol. 2004:58:453-88.

89. Dutta S, Kundu A, Chakraborty M, Ojha S, Chakrabarti J, Chatterjee N. Production and optimization of Fe (III) specific ligand, the siderophore of soil inhabiting and wood rotting fungi as deterrent to plant pathogens. Acta Phytopathol Entomol Hung. 2006;41(3-4):237-48.

90. Jadhav HP, Shaikh SS, Sayyed RZ. Role of hydrolytic enzymes of rhizoflora in biocontrol of fungal phytopathogens: an overview. In: Mehnaz S (ed.) Rhizotrophs: plant growth promotion to bioremediation, microorganisms for sustainability 2. Springer Nature Singapore Pte Ltd. 2017;183. DOI https:// doi.org/10.1007/978-981-10-4862-3-9.

91. Parker CT, Tindall BJ, Garrity GM. International code of nomenclature of prokaryotes: prokaryotic code (2008 revision). Int J Syst Evol Microbiol. 2019; 69(1A):S1-S111.

92. Meier-Kolthoff JP, Klenk H-P, Göker M. Taxonomic use of DNA G+ C content and DNA-DNA hybridization in the genomic age. Int J Syst Evol Microbiol. 2014;64(2):352-6.

93. Richter M, Rosselló-Móra R. Shifting the genomic gold standard for the prokaryotic species definition. Proc Natl Acad Sci. 2009;106(45):19126-31.

94. Abuzinadah $R$, Finlay $R$, Read $D$. The role of proteins in the nitrogen nutrition of ectomycorrhizal plants. New Phytol. 1986;103(3):495-506.

95. Yoon S-H, Ha S-M, Lim J, Kwon S, Chun J. A large-scale evaluation of algorithms to calculate average nucleotide identity. Anton. Leeuw. Int.J.G. 2017;110(10):1281-6.

\section{Publisher's Note}

Springer Nature remains neutral with regard to jurisdictional claims in published maps and institutional affiliations.

Ready to submit your research? Choose BMC and benefit from:

- fast, convenient online submission

- thorough peer review by experienced researchers in your field

- rapid publication on acceptance

- support for research data, including large and complex data types

- gold Open Access which fosters wider collaboration and increased citations

- maximum visibility for your research: over $100 \mathrm{M}$ website views per year

At BMC, research is always in progress.

Learn more biomedcentral.com/submission 